\title{
Exploration of Threshold Analysis in the Relation between Urbanization and Carbon Emissions: The Case of China
}

\author{
Qiuyuan Sun1, Mingyue Wang² \\ ${ }^{1}$ College of Economics, Jinan University, Guangzhou, Guangdong \\ ${ }^{2}$ School of Public Policy and Management, University of Chinese Academy of Sciences, Beijing, China \\ Email: sun.qiuyuan@163.com,wangmingyue16@mails.ucas.ac.cn,yya@sam.sdu.dk
}

How to cite this paper: Sun, Q.Y. and Wang, M.Y. (2018) Exploration of Threshold Analysis in the Relation between Urbanization and Carbon Emissions: The Case of China. Open Journal of Business and Management, 6, 438-453.

https://doi.org/10.4236/ojbm.2018.62032

Received: December 19, 2017

Accepted: April 27, 2018

Published: April 30, 2018

Copyright ( $) 2018$ by authors and Scientific Research Publishing Inc. This work is licensed under the Creative Commons Attribution International License (CC BY 4.0).

http://creativecommons.org/licenses/by/4.0/

\begin{abstract}
In the process of urbanization, energy consumption has significant effect on carbon emissions. The aim of this paper is to analyze the impact of urbanization on carbon emissions for different income levels across 29 provinces of China during 1995-2015. The improved STIRPAT model provides the theoretical foundation for this research. Then, the threshold analysis was used to assess the effect of urbanization on carbon emissions. On the basis of the average annual income, two threshold points that divide the whole sample into three groups were identified, namely, 1) an average annual income of 7400 $\mathrm{RMB}$ and 2) an average annual income of $16,250 \mathrm{RMB}$. The result shows that effect of urbanization on $\mathrm{CO}_{2}$ emissions varies in terms of income stages and specific regions. Finally, the policy implication was discussed.
\end{abstract}

\section{Keywords}

Urbanization, Carbon Emissions, Threshold Model, Urbanization and Carbon Emissions

\section{Introduction}

The rate of urbanization in China has increased considerably over the past decades. As a result, the share of population lived in urban areas has been doubled since 1990s. Specifically, there was only about $26 \%$ of the total population lived in urban areas in 1990 , but the share increased to $56 \%$ by the end of 2015 . According to China's Ministry of Housing and Urban-Rural Development, there are about 300 million rural inhabitants will move to urban areas from 2010 to 2025. The distribution of population in China is quite uneven. Inhabitants living 
in the rural areas are mostly sporadic scattered across the country whereas the top ten most populous cities accounts for about $10 \%$ of the entire population. Due to the rapid economic growth, not only mega, large and middle-sized cities are growing, but also small cities and towns are emerging in recent years. Put differently, more and more rural inhabitants moved to the urban regions. This underlines that urbanization in China is at a high growth rate. Urbanization will not only bring significant changes for citizens such as changing of their lifestyles but also for public infrastructures such as public utilities, hospitals, schools and nursing homes etc. Given the increasing establishment of urban infrastructure, urbanization can help the efficiency of transportation and thereby reduce the energy consumption in the transportation sector [1]. Furthermore, the other benefit of urbanization lies in promoting optimization of resources utilization, i.e., it can attract more and more capital and talent flow into urban area and thereby improve the utilization of resources [2].

An emergent problem of urbanization is that of the increasing human activities in urban areas will result in severe pressure on the environment such as carbon emission. A research [3] found that the increasing construction and maintaining of the urban public infrastructure due to urbanization will lead to an increase in energy use. In a study of investing the effect of urbanization in the Yangtze River Delta region in China [4], Gu et al. found that carbon emissions from transport, household and industrial activities are major contributors for climate change, which eventually lead to environmental threats such as flooding, dryness etc. [5]. In the same vein, Parikh and Shukla assessed the consequences on greenhouse emissions from urbanization for developing countries during 1965-1987, and found that urbanization will lead to a concentration of industrial production and changes in the individuals' consumption patterns and lifestyles, which in turn will increase energy use and thereby increase greenhouse gases emissions. It is estimated that carbon dioxide emissions accounts for about 70\% of the global greenhouse gases emissions, which are believed to be main contributor for global warming following IPCC (2007). There have seen rapid growth in urbanization worldwide, therefore, how to constrain the carbon emissions from urbanization becomes an urgent problem. In conclusion, previous research have reached a consensus that urbanization have different influence on the environment, and the eventual environmental effect may be attribute to different factors and the interaction of these factors. For example, the environmental effect from different phases of urbanization appeared to be different. Therefore, some researchers claimed that the phase of urbanization should be considered when evaluating the effect of urbanization on the environment [6]. The numerical value used for classification of the different phase of urbanization can be either discrete or continuous. Furthermore, due to the lack of a widely-accepted standard, the classification of phases of urbanization differs significantly among studies [7]. Finally, the classification of phases of urbanization often ignores the fact that one geographical area (in particular when it covers a large area) might 
have several different phases of urbanization. As an example, the phase of urbanization is totally different in the Pearl River Delta Zone of Guangdong Province in China from its northern and western part. Unfortunately, current research has simply classified the whole Guangdong province as highly developed region when studying the effect of urbanization in China. Apparently, this rough classification may bring accuracy problems in the estimation. It is therefore important to find a threshold value for the classification of phase of urbanization. Based on the threshold value, we can then segment the sample into different categories (i.e., phases of urbanization). The advantage of using a threshold model is a measure of accuracy that is independent of the particular threshold adopted.

The objective of the paper is to investigate the impact of urbanization on carbon emissions in China. There are several reasons for this. Firstly, China is the world's largest $\mathrm{CO}_{2}$ contributor, and is estimated that $\mathrm{CO}_{2}$ will reach to a peak in 2030. Secondly, the rate of urbanization is creasing considerably because of the industrialization and will continue to grow in the next decades. Prior research has proved that the growing of urbanization will bring an increasing of $\mathrm{CO}_{2}$ emission. Thirdly, China has committed to reduce emissions intensity of the economy by $60 \%$ - 65\% compared with 2005 in the Paris Climate Agreement in 2015.

The study will contribute to the literature on urbanization and carbon emission using an explorative threshold analysis. The study differs from previous studies that it spells out the threshold value for classifying the different stage of urbanization, namely, it splits the sample into three different areas with different phases of urbanization rather than a simple classification. The rest of the paper is organized as following. Section 2 presents literature review. Section 3 describes the empirical model, variables and data. Section 4 describes and discusses the results. Section 5 concludes the study and provides policy implications.

\section{Literature Review}

Much research has been conducted in investigating the effect of urbanization on carbon emissions under different research contexts. Parikh \& Schukla [8] concluded that urbanization has two distinct consequences on the environment: 1) urbanization will increase the density and thus demand more infrastructure capacity and resources and consequently it burdens the local environment, and 2) the agglomeration effect of urbanization can boost energy efficiency due to a reduced need for a proliferation of public facilities in a less dispersed settlement pattern.

The findings of current literature on investigating the effect of urbanization on carbon emissions appear to be different from case to case, some are even controversial. The results of current literature can be divided into three categories: 1) positive effect, 2) negative effect and 3) inverted U-shaped effect. The outcome of different effect is mainly attributed to the fact that the modeling ap- 
proach. The positive and negative effect model was captured by the linear regression whereas the inverted $U$-shaped effect was captured by the non-linear regression. Table 1 provides an overview of the literature.

Apparently, the majority of the literatures are in line with the findings of $\mathrm{Pa}$ rikh \& Shukla, that is, urbanization has positive effect on $\mathrm{CO}_{2}$ emissions. York used a regression analysis to investigate the relationship between urbanization and energy consumption within $14 \mathrm{EU}$ members and found that urbanization has a positive effect on energy consumption [9]. Liddle and Lungfound that urbanization had positive effects on carbon emissions in a study of urbanization and carbon emission among 17 developed countries [10]. Lin and Liu investigated the effect of the extent of economic development and urbanization on carbon emission using an integration approach [11]. They found that both the extent of economic development and urbanization had significant positive effects on carbon emissions. Wang and Shao found that the rapid economic development and urbanization did increase carbon emission in China on the provincial level. This is because when people migrate from rural areas to urban areas, they will take part in non-agricultural activities such as public construction. These non-agriculture activities will consequently increase energy consumption and thereby carbon emissions. Al-mulali et al. examined the relationship between urbanization, energy consumption and $\mathrm{CO}_{2}$ emissions for the MENA countries from 1980 to 2009, and found that there is a long run bi-directional casual relationships between the variables [12]. Peng et al. used STIRPAT model to analyze the impacts of urbanization on carbon dioxide emissions on a province-level data in China from 1995-2011, indicating that rapid

Table 1. Overview of literature on the effect of urbanization on carbon emissions.

\begin{tabular}{ccc}
\hline $\begin{array}{c}\text { The effect of urbanization on carbon } \\
\text { emissions }\end{array}$ & Authors & Research setting \\
\hline & Gouldson \& Murphy (1997) & \\
& York et al. (2003) & 137 counties \\
& York (2007) & 14 EU nations \\
Lositive & Liddle \& Lung (2010) $~$ & 17 developed countries \\
& Usama Al-mulali et al. (2013) & MENA countries \\
& Ponce \& Maishall (2014) & 80 countries \\
& Wang \& Shao (2014) & China \\
& Peng et al. (2016) & China \\
& Pachauri \& Jiang (2008) & India \& China \\
Negative & Alexiadis 2012 & China \\
& Li et al. (2014) & OECD countries \\
& Zhang et al. (2017) & China \\
\hline
\end{tabular}


urbanization can increase carbon dioxide emissions both in the short-run and the long-run [13]. In a study on investigating the relationship between carbon emissions and urbanization and environmental policies, Ponce and Maishall suggested that the elasticity of urbanization-emissions is 0.95. Furthermore, Ponce and Maishall [14] pointed out countries with relatively stronger environmental policies or with relatively high income were better than its counter partners to control $\mathrm{CO}_{2}$ level. Finally, the ecological modernization theory claims that urbanization will lead to an institutional society transformation, which in turn resulting in increasing carbon dioxide emission [15]. The second category, namely urbanization will have negative effect on carbon emissions were also found in a number of researches. Pachauri \& Jiang suggested that urbanization can help reduce energy consumption and carbon emissions in India [16]. They argued that rural residents in Indian are heavily dependent on inefficient solid fuels which produce much carbon emissions. The findings of Pachauri \& Jiang are in line with the new economic geography and endogenous growth theory. Both the new economic geography and endogenous growth theory suggested that population agglomeration may result in technological development which eventually leads to energy efficiency, and the industrial agglomeration from urbanization could facilitate central control of carbon emission [17]. The transformation and upgrading of industrial structure may lead to optimize of energy resources utilization.

The third category, is the inverted U-shape effect between carbon emission and urbanization. In these findings, urbanization was divided into different stages. In the beginning phase of urbanization, energy consumption is increasing. In the late phase of urbanization, the emerging of new energy technology such as energy inefficiency technology, will lead to a decrease in energy consumption. Li et al. set up GMM model based on China province-level data from 2000 to 2011, showing that there is an inverted " $U$ " type environmental Kuznets curve in China [18]. Similarly, Zhang et al. used two-way fixed effects model based on the extended STIRPAT theoretical framework to analyze the relationship between urbanization and carbon emissions and found that there is an inverted U-shaped between them in OECD countries [19]. He et al. categorized China's 29 provinces into three regions based on the development level, and found that there is an inverted U-shaped relationship between urbanization and carbon emissions [20]. The three categories reflects indeed reflect the stage of urbanization.

The differences in conclusions lie in the exogenous conditions such as the selection of research area and different economic level. To accommodate the exogenous problem, Poumanyvong \& Kaneko used simple classification of 99 countries, dividing the 99 countries into three regions. Likewise, Zhang \& Lin grouped China's 29 provinces into eastern, central and western regions. The simple classification may cause problem. As an example, when eastern region is regarded as a high economic development area, central region is regarded as 
middle economic development area, and western region is regarded as low economic development area, we found that some cities in the western area has as high level of economic development as cities in the eastern area and vice versa. Consequently, it will have influence on the final conclusion. However, the non-linear model also has limitation. York et al. found that the nonlinear relationship between urbanization and carbon emissions is insignificant [21]. In this paper, we decided to use the threshold model, and used the economic development level as threshold variable to analyze the impacts of urbanization on carbon emissions in order to accommodate the model limitations from previous studies.

\section{Models, Variables and Data}

\subsection{Models}

\subsubsection{Theoretical Model-Extended STIRPAT}

Enrlich and Holdren proposed IPAT model to describe the effect of economic activities on the environment [22]. The general form of an IPAT function takes the following form:

$$
I=P A T
$$

where $I$ represents the environmental impact, $P$ represents population size, $A$ represents per capita wealth and $T$ represents technology.

One limitation of this specification is that there is no single factor can be explained for the environmental impact. As an example, if $A$ and $T$ remain constant while $P$ decreases during a time period in a given situation, it will be incorrect to say that $P$ alone will have impact on environment. This is because $A$ and $T$ remain unchanged, which may scale the effect of changes in $P$.

In order to overcome this problem, Dietz and Rosat [23] STIRPAT model rewrote by. The general form of STIRPAT model can be specified as follows:

$$
I=a P^{b} A^{c} T^{d}
$$

It is constructed to find the stochastic approximation by analyzing the regression of population size $(P)$, per capita wealth $(A)$ and technology $(T)$. There is the logarithmic form of the function:

$$
\ln I=\ln a+b(\ln P)+c(\ln A)+d(\ln T)+\ln e
$$

The regression coefficients $b, c, d$ of the function are the elasticities of the independent variables. The dependent variable will change according to the coefficient when one of the independent variables changes by $1 \%$, while keeping other variables constant. The STIRPAT model is the fundamental of the empirical model specified below in this study.

\subsubsection{Empirical Model-Threshold Model}

Hansen (1999) presented threshold model which locates key threshold points and analyzed regression according to set stages [24]. The general threshold mode is as follows: 


$$
y_{i t}=u_{i}+\beta_{1} d_{i t} I\left(q_{i t} \leq \gamma_{1}\right)+\beta_{2} d_{i t} I\left(\gamma_{1} \leq q_{i t} \leq \gamma_{2}\right)+\beta_{3} d_{i t} I\left(q_{i t}>\gamma_{2}\right)+\theta^{\prime} x_{i t}+\varepsilon_{i t}
$$

where $q_{i t}$ is threshold variable, $\gamma$ is threshold point by grid searching to achieve $\hat{\gamma}=\arg \min S(\gamma)$. The likelihood ratio (LR) test was used to ascertain the accuracy of the estimated results:

In this study, we integrate the threshold model and STIRPAT model to investigate the impact of driving factors for the $\mathrm{CO}_{2}$ emissions, with a particular focus on the relationship between $\mathrm{CO}_{2}$ emissions and urbanization. Per gross domestic product is set as threshold variable. The model is specified as following:

$$
\begin{aligned}
\ln C_{i t}= & \alpha+\beta_{1}\left(\ln U R_{i t}\right) * I\left(p g d p_{i t} \leq \lambda_{1}\right)+\beta_{2}\left(\ln U R_{i t}\right) * I\left(\lambda_{1}<p g d p_{i t} \leq \lambda_{2}\right) \\
& +\beta_{3}\left(\ln U R_{i t}\right) * I\left(\lambda_{2}<p g d p_{i t}\right)+\beta_{4} \ln P_{i t}+\beta_{5} p g d p_{i t}+\beta_{6}\left(p g d p_{i t}\right)^{2} \\
& +\beta_{7} \ln \left(E I_{i t}\right)+\beta_{8} \ln \left(I S_{i t}\right)+\beta_{9} \ln \left(T E_{i t}\right)+\mu_{i}+\varepsilon_{i t}
\end{aligned}
$$

The definition of variables is shown in Table 2.

\subsection{Variables and Data}

We use carbon emission as the dependent variable in the model estimation. There are several reasons for this. This is because $\mathrm{CO}_{2}$ emissions account for about $70 \%$ of the global greenhouse gases (GHGs) emissions. $\mathrm{CO}_{2}$ is also believed to be main contributor for global warming following IPCC (2007). In line with Ehrlich and Holdren and Al-Mulali et al., we choose $\mathrm{CO}_{2}$ as an index of environmental quality, which describes the environmental effect of $\mathrm{CO}_{2}$. The computation of $\mathrm{CO}_{2}$ can be found in the Appendix.

Six explanatory variables were included in the model estimation. These are: 1) urbanization (UR), 2) GDP per capita (pgdp), 3) population (P), 4) energy intensity (EI), 5) the proportion of secondary industry (IS), 6) technology (TE). The variable, Urbanization (UR), is measured by the percentage of population in urban agglomeration. The energy intensity (EI) is measured by the energy effi-

\begin{tabular}{|c|c|c|c|c|}
\hline & Symbol & Variable & Definition & Unit \\
\hline $\begin{array}{l}\text { Dependent } \\
\text { variable }\end{array}$ & $\mathrm{C}$ & $\mathrm{CO}_{2}$ emissions & Total Carbon emission of each province & Kiloton \\
\hline \multirow{6}{*}{$\begin{array}{l}\text { Explanatory } \\
\text { variable }\end{array}$} & UR & Urbanization & $\begin{array}{l}\text { The share of urban population in the } \\
\text { total population of each province }\end{array}$ & $\%$ \\
\hline & IS & Industry structure & Proportion of secondary industry & $\%$ \\
\hline & EI & Energy intensity & $\begin{array}{c}\text { Energy consumption per gross domestic } \\
\text { product }\end{array}$ & $\begin{array}{l}\text { Tce per } 10^{4} \\
\text { RMB Yuan }\end{array}$ \\
\hline & pgdp & GDP per capita & $\begin{array}{l}\text { Representing the level of economic } \\
\text { development }\end{array}$ & $10^{4}$ yuan \\
\hline & $\mathrm{P}$ & Population & The total population of each province & 104 \\
\hline & $\mathrm{TE}$ & Technology & Total number of patents & unit \\
\hline
\end{tabular}
ciency of a nation's economy [25]. GDP per capita (pgdp) measures the impact of demographic and economic development. The Proportion of secondary

Table 2. The definition of variables used in the study.

Note: Data sources from China Statistical Yearbook and the China Statistical Yearbook. 
industry (IS) measures the impact of the second industry's production on carbon emissions. Technology (TE) is used to capture how technology changes the efficiency of production and the way of household's consumption. The description of these variables is presented in the Table 2.

In the model estimation, we choose GDP per capita as the threshold variable. For the consistency with the form of threshold model we do not take the logarithm for the GDP per capita index. Linear and non-linear pgdp and pgdp2 are added in the model to test whether the result supports the hypothesis that the relationship between economic growth and $\mathrm{CO}_{2}$ emissions exhibits an inverted U-shaped.

The data used in this study consists of 29 provinces in China from 1995-2015. All data are attained from the China Statistical Yearbook and the China Energy Statistical Yearbook. The descriptive of variables is described in the Table 3.

\section{Empirical Result}

As shown in Table 4, the threshold points are 0.740 and 1.625 and are significant at $5 \%$ level. Figure 1 is the confidence interval construction in single threshold model. All of them pass LR test. Figure 2 and Figure 3 are the confidence interval construction in double threshold model in first and second round, respectively.

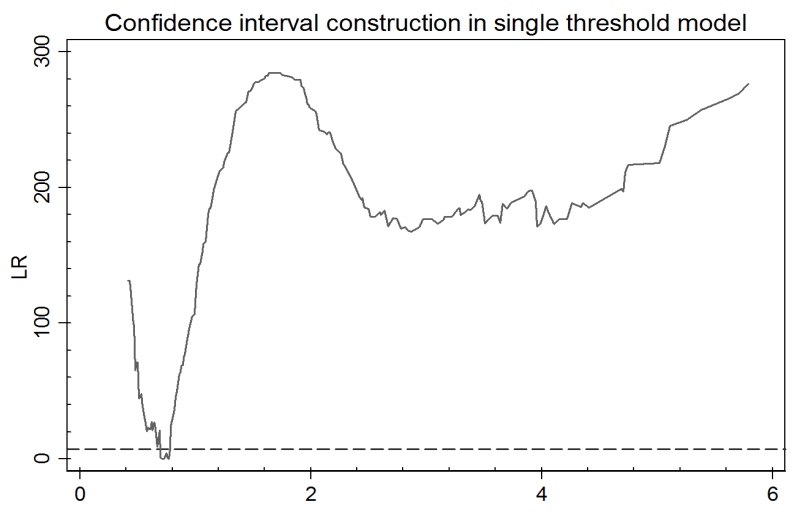

Figure 1. Confidence interval construction in single threshold model.

Table 3. Descriptive statistics of variables.

\begin{tabular}{ccccccccc}
\hline Variable & Obs & Mean & Std. Dev. & Min & p25 & p50 & p75 & $\max$ \\
\hline $\ln \mathrm{C}$ & 609 & 8.48852 & 0.9328333 & 4.987 & 7.965 & 8.561 & 9.069 & 10.692 \\
$\ln \mathrm{P}$ & 609 & 8.129299 & 0.7806664 & 6.176 & 7.777 & 8.249 & 8.722 & 9.292 \\
$\ln \mathrm{NR}$ & 609 & 3.561225 & 0.675903 & -0.211 & 3.279 & 3.722 & 3.972 & 4.495 \\
$\operatorname{pgdp}$ & 609 & 2.235567 & 2.076292 & 0.020 & 0.670 & 1.460 & 3.240 & 10.690 \\
$\operatorname{lnEI}$ & 609 & 0.3856478 & 0.694165 & -1.347 & -0.083 & 0.344 & 0.820 & 3.773 \\
$\operatorname{lnIS}$ & 609 & 3.807495 & 0.2048741 & 2.850 & 3.721 & 3.859 & 3.944 & 4.179 \\
$\ln \mathrm{TE}$ & 609 & 8.15038 & 1.688959 & 3.761 & 7.043 & 8.001 & 9.257 & 12.506 \\
\hline
\end{tabular}




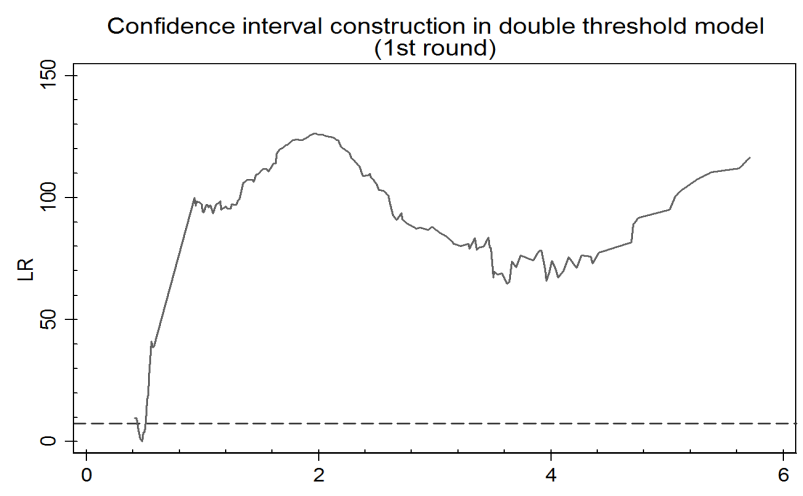

Figure 2. Confidence interval construction in double threshold model (1st round).

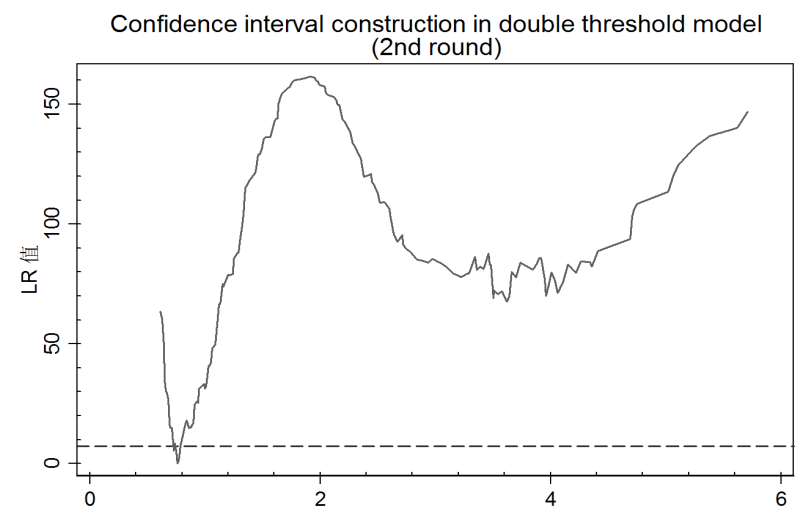

Figure 3. Confidence interval construction in double threshold model (2nd round).

Table 4. Estimated threshold values.

\begin{tabular}{lcc}
\hline & Estimate & $95 \%$ confidence interval \\
\hline$\gamma_{1}$ & 0.740 & {$[0.700,0.770]$} \\
$\gamma_{2}$ & 1.625 & {$[1.510,1.860]$} \\
\hline
\end{tabular}

The Equation (5) specifies the empirical model as following,

$$
\begin{aligned}
\ln C_{i t}= & \alpha+\beta_{1}\left(\ln U R_{i t}\right) * I\left(\operatorname{pgdp}_{i t} \leq \lambda_{1}\right) \\
& +\beta_{2}\left(\ln U R_{i t}\right) * I\left(\lambda_{1}<p g d p_{i t} \leq \lambda_{2}\right) \\
& +\beta_{3}\left(\ln U R_{i t}\right) * I\left(\lambda_{2}<p g d p_{i t}\right) \\
& +\beta_{4} \ln P_{i t}+\beta_{5} g d p_{i t}+\beta_{6}\left(g p d_{i t}\right)^{2} \\
& +\beta_{7} \ln \left(E I_{i t}\right)+\beta_{8} \ln \left(I S_{i t}\right)+\beta_{9} \ln \left(T E_{i t}\right)+\mu_{i}+\varepsilon_{i t}
\end{aligned}
$$

where $\mu_{i}$ captures the individual effects, a represents constant term, $\varepsilon_{i t}$ is the residual error term.

The empirical results are reported in Table 5. In the model estimation, we used both the OLS and threshold model to capture the effect of urbanization on $\mathrm{CO}_{2}$ emission. It appears that all coefficients of explanatory variables had the 
Table 5. The result of threshold model.

\begin{tabular}{|c|c|c|c|c|}
\hline & \multicolumn{2}{|c|}{ OLS estimation } & \multicolumn{2}{|c|}{ Threshold analysis } \\
\hline & & & Random effect & Fixed efect \\
\hline \multirow[t]{2}{*}{$\ln \mathrm{P}$} & $0.685^{\star * *}$ & $0.880^{\star * *}$ & $0.886^{* * *}$ & $0.810^{* * *}$ \\
\hline & $(22.113)$ & $(42.040)$ & (38.709) & $(9.770)$ \\
\hline \multirow[t]{2}{*}{ pgdp } & $0.181^{* * *}$ & $0.622^{* * *}$ & $0.448^{* * *}$ & $0.377^{\star * *}$ \\
\hline & $(10.994)$ & $(20.168)$ & $(20.238)$ & $(18.219)$ \\
\hline \multirow[t]{2}{*}{ Pgdp 2} & & $-0.042^{\star * *}$ & $-0.027^{\star * *}$ & $-0.023^{* * *}$ \\
\hline & & $(-14.060)$ & $(-14.197)$ & $(-13.205)$ \\
\hline \multirow[t]{2}{*}{$\ln E I$} & $0.798^{* * *}$ & $0.847^{\star * *}$ & $0.780^{* * *}$ & $0.596^{* * *}$ \\
\hline & $(19.335)$ & $(16.452)$ & $(43.809)$ & $(26.021)$ \\
\hline \multirow[t]{2}{*}{$\operatorname{lnIS}$} & $0.857^{* * *}$ & $0.473^{* * *}$ & $0.508^{\star * *}$ & $0.579^{* * *}$ \\
\hline & $(9.003)$ & $(4.165)$ & $(10.482)$ & (10.399) \\
\hline \multirow[t]{2}{*}{$\ln T E$} & $0.213^{\star * *}$ & $0.065^{\star * \star}$ & $0.042^{\star * *}$ & $0.079^{* * *}$ \\
\hline & $(8.332)$ & $(3.626)$ & $(2.972)$ & $(5.333)$ \\
\hline \multirow[t]{2}{*}{$\ln U R$} & $0.229^{* * *}$ & $0.156^{* * *}$ & $0.190^{* * *}$ & $0.171^{\star * *}$ \\
\hline & $(5.049)$ & $(3.461)$ & $(12.370)$ & $(11.248)$ \\
\hline \multirow[t]{2}{*}{$\ln \mathrm{UR}^{\star} \mathrm{d} 1$} & & & $-0.103^{\star * *}$ & $-0.097^{* * *}$ \\
\hline & & & $(-15.962)$ & $(-16.591)$ \\
\hline \multirow[t]{2}{*}{$\ln \mathrm{UR}^{\star} \mathrm{d} 2$} & & & $0.025^{\star * *}$ & $0.021^{\star \star \star}$ \\
\hline & & & $(3.495)$ & $(3.339)$ \\
\hline \multirow[t]{2}{*}{ _cons } & $-3.604^{\star * *}$ & $-2.878^{\star \star \star}$ & $-2.692^{\star * *}$ & $-2.377^{* * *}$ \\
\hline & $(-9.293)$ & $(-7.202)$ & $(-14.135)$ & $(-3.304)$ \\
\hline $\mathrm{N}$ & 609 & 609 & 609 & 609 \\
\hline $\mathrm{R}^{2}$ & 0.912 & 0.956 & 0.933 & 0.942 \\
\hline
\end{tabular}

Note: $\mathrm{t}$ statistics in parentheses ${ }^{*} \mathrm{p}<0.10,{ }^{* *} \mathrm{p}<0.05,{ }^{* * *} \mathrm{p}<0.01$

expected sign, and the goodness of fit measurements indicates that the models are acceptable. However, the OLS models ignore the fact that the degree of the urbanization may have different influence depending on the economic development levels. Thus, we decided to use the threshold model in this paper. We estimate the threshold model both with random effect and with fix-effect. However, the results of Hausman tests show that the null hypothesis of random effect (i.e., difference in coefficients not systematic) is rejected. Therefore, we adopt the fixed effect to estimate the effects of urbanization on carbon emission.

As expected, population, GDP per capital, energy intensity, the proportion of secondary industry and technology have positive effect $\mathrm{CO}_{2}$ emission across all models. The positive effect of GDP per capita and the negative effect of the quadratic term of GDP per capita in the estimation satisfied the environmental Kuznets curve. The Kuznets curves show that $\mathrm{CO}_{2}$ emission tends to increase as 
the economic is growing in the very beginning of the urbanization phase.

From Table 4, we identified two threshold points, i.e., 0.740 and 1.625. This can be used to divide the economic development into three levels across China. The lowest level is the average annual income is lower than $7400 \mathrm{RMB}$. The second level lies in where the average annual income is between $7400 \mathrm{RMB}$ and $16,250 \mathrm{RMB}$, and the third level is when the average annual income is higher than 16,250 RMB.

As shown in the column 4 , the key variables are $\ln U R$ and $\ln U R * d_{i}, d_{i}$ is a dummy variable used to distinguish the level of economic development, $\mathrm{d} 1=1$ when economic level is lower than 0.740 , which means that the average annual income of below $7400 \mathrm{RMB}$ (the first stage), otherwise $\mathrm{d} 1=0$. The coefficient of $\mathrm{CO}_{2}$ emissions with respect to urbanization is $0.074\left(\ln \mathrm{UR}+\ln \mathrm{UR}{ }^{*} \mathrm{~d} 1\right)$ which is significant but very small. Liddle and Lung found that urbanization had positive but statistically non-significant effects on carbon emissions. In the early stage of economic development, with limited resources, more people came into cities, but there are not enough capital to invest including public facilities and private sectors. When income level reach $7400 \mathrm{RMB}$, in the second stage, the driving strength of urbanization on $\mathrm{CO}_{2}$ emissions increased as reflected in the coefficient rise from 0.074 to 0.171 . In the higher economic level, people have more consumer power. Madlener and Sunak found that different processes and mechanisms of urbanization substantially affect urban structures as well as human behavior, and thereby affect energy demand [26]. More rural residents migrate from rural to urban areas as people may change their pattern of energy consumption and get energy easier and consume more energy. Holtedahl and Joutz [27] argued that moving from rural to city migrate increases their accessibility to electricity and household are likely to increase their use of existing applicants and purchase of new ones. China is the largest country of vehicles consumption, and people who migrate to cities arouse more consumption of private cars, which leading to more carbon emissions. Weber and Matthews [28] suggested that dietary shift can be a more effective means of lowering an average household's food-related carbon and location of food is also an important factor relate to carbon emission. Dummy variable $\mathrm{d} 2=1$ when income level up to 16,250 RMB (second threshold point is 1.6250), otherwise $\mathrm{d} 2=0$. The coefficient of $\mathrm{CO}_{2}$ emissions with respect to urbanization is $0.193(\ln U R+\ln U R * d 2)$ when income level is higher than $16250 \mathrm{RMB}$, which became stronger but similar to second stage. Zhu \& Peng [29] found that carbon emission-promoting effect of urbanization is bigger than its mitigating effect through assembly and scale effects. In this stage, technology development is a key factor which improves efficient use of resources [30]. Believed that urbanization affects energy consumption patterns in four ways and technology improvement is one of important factor. But we can see that the elasticity of $\mathrm{CO}_{2}$ emissions with respect to technology is 0.079 which is positive and significant. On the one hand, technology development control carbon emissions through improving efficiency and scale ef- 
fect and that is why the urbanization has similar impacts on carbon emissions in the third stage with the second stage. On the other hand, technology development offers more convenience for people to acquire energy and consume more energy and result to more industry and equipment rebuilt. Total effect of technology on carbon emissions is positive.

In earlier stage of economic development, expansion in the scale of the economy leads to negative environmental impacts because there is no technological change. In higher level of economic development, the industry structure change towards and services, coupled with increased environmental awareness, leading to a reduction in environmental degradation. The estimated coefficient of secondary shows that $1 \%$ increase on the ratio of change of secondary industry structure will lead to $0.579 \%$ increase in carbon emissions, indicating that coal-intensive industry has a significant impact on $\mathrm{CO}_{2}$ emissions. Low carbon industries and information-intensive industries are advocated. In China, coal occupied main part of energy consumption structure. Using the non-coal energy is an effective mechanism to lower carbon emissions. Non-coal energy such as nuclear power, wind power and solar are important and efficient energy sources which facilitating the transition of the industrial structure. Technology has also dual effect toward carbon emissions, and reasons still need to be found.

The coefficient of energy intensity is 0.596 . It indicates that $1 \%$ growth in the coal intensity of total energy consumption has a positive effect of $0.596 \%$ on carbon emissions increasement. Energy policies that promote energy efficiency across all sectors are needed and new technology should be applied to different manufacturing industries.

\section{Conclusions and Policy Implications}

In this paper, we integrate both the STIRPAT model and the threshold model to explore the impact of urbanization on carbon emissions. We use the threshold points of economic development to divide the whole sample into three groups and it shows that urbanization has different effects on $\mathrm{CO}_{2}$ emissions in different income stages and specific regions. Furthermore, industry structure, energy intensity, technology and population also play significant role in carbon emissions.

In the process of urbanization, immigrants may change their life-style and the government may invest basic public facilities, which pose a significant influence on national energy structure. All of these human activities relate to energy consumption which directly affect carbon emission. On the one hand, some found that energy used for production and residential consumption and for requirements of infrastructure and residential dwellings increased along with urbanization [27]. Similarly, Holtedahl and Joutz found that migrants increase their accessibility to electricity and households are likely to increase their use of existing applicants and even purchase of new ones, which leads to more energy consumption. On the other hand, population aggregation may yield new ways of production such as bicycle-sharing, offering a low-carbon travel mode and re- 
ducing congestion. The economic effect of urbanization is bigger than scale effect, and the impact of urbanization on $\mathrm{CO}_{2}$ emissions presents a gradual upward trend. China is in the fast economic development stage, facing both the increasing pressure for carbon reduction and the threat of domestic energy shortages. Lin and Liu believed that controlling the pace of urbanization and taking energy conservation are realistic and feasible measures to reduce carbon emissions [31]. Green and low-carbon transportation tools are thus encouraged to use in public. China will definitely move away from current coal-intensive energy economic structure to a more efficient energy development stage. Given the constraints of natural resources, policies will need to be encouraged in exploiting new energy and energy technology across all sectors. Put differently, future policy will have to focus more on the development of clean energy. Renewable energy such as hydro energy, wind power and solar are important and efficient energy sources which driving the change of industrial structure into a green and efficient way.

Our research provides a new perspective to understand the relationship between and carbon emissions and other main factors. But there are still some limits, different age component of rural migrants can also have different effect on carbon emissions in the process of urbanization, which leads to a further research.

\section{References}

[1] Shao, C., Guan, Y., Wan, Z., et al. (2014) Performance and Decomposition Analyses of Carbon Emissions from Industrial Energy Consumption in Tianjin, China. Jour nal of Cleaner Production, 64, 590-601. https://doi.org/10.1016/j.jclepro.2013.08.017

[2] Wang, Z., Zhu, Y., Zhu, Y., et al. (2016) Energy Structure Change and Carbon Emission Trends in China. Energy, 115, 369-377. https://doi.org/10.1016/j.energy.2016.08.066

[3] Weber, C.L. and Matthews, H.S. (2008) Food-Miles and the Relative Climate Impacts of Food Choices in the United States. Environmental Science \& Technology, 42, 3508-3513. https://doi.org/10.1021/es702969f

[4] Chao-Lin, G.U., Zhang, X.M. and Wang, X.D. (2011) Climate Change, Urbanization and the Yangtze River Delta. Resources \& Environment in the Yangtze Basin, 20, 1-8.

[5] Zhang, Y., Cao, Y. and Dai, J. (2015) Quantification of Statistical Uncertainties in Performing the Peak over Threshold Method. Journal of Marine Science \& Technology, 23, 717-726.

[6] Gu, C., Tan, Z. and Liu, W. (2009) A Study on Climate Change, Carbon Emissions and Low-Carbon City Planning. Urban Planning Forum, 22, 38-45.

[7] Zhang, N., et al. (2017) How Does Urbanization Affect Carbon Emissions? A Cross-Country Panel Data Analysis. Energy Policy, 107, 678-687.

[8] Ponce, L.B.D. and Marshall, J.D. (2014) Relationship between Urbanization and $\mathrm{CO}_{2}$ Emissions Depends on Income Level and Policy. Environmental Science \& Technology, 48, 3632-3639. https://doi.org/10.1021/es405117n 
[9] York, R., Rosa, E.A. and Dietz, T. (2003) STIRPAT, IPAT and ImPACT: Analytic Tools for Unpacking the Driving Forces of Environmental Impacts. Ecological Economics, 46, 351-365. https://doi.org/10.1016/S0921-8009(03)00188-5

[10] Liddle, B. (2010) Age-Structure, Urbanization, and Climate Change in Developed Countries: Revisiting STIRPAT for Disaggregated Population and Consumption-Related Environmental Impacts. Population \& Environment, 31, 317-343. https://doi.org/10.1007/s11111-010-0101-5

[11] Liu, Y., Xiao. H., Lv, Y., et al. (2015) The Effect of New-Type Urbanization on Energy Consumption in China: A Spatial Econometric Analysis. Journal of Cleaner Production, 163, S299-S305. https://doi.org/10.1016/j.jclepro.2015.10.044

[12] Al-Mulali, U., Fereidouni, H.G., Lee, J.Y.M., et al. (2013) Exploring the Relationship between Urbanization, Energy Consumption, and $\mathrm{CO}_{2}$ Emission in MENA Countries. Renewable \& Sustainable Energy Reviews, 23, 107-112. https://doi.org/10.1016/j.rser.2013.02.041

[13] Wang, N. and Al, E. (2016) Nuclear Structure in China 2014. World Scientific Publishing Co., Singapore.

[14] Poumanyvong, P., Kaneko, S. and Dhakal, S. (2012) Impacts of Urbanization on National Transport and Road Energy Use: Evidence from Low, Middle and High Income Countries. Idec Dp2, 46, 268-277.

[15] Gouldson, A. and Murphy, J. (1997) Ecological Modernisation: Economic Restructuring and the Environment. Blackwell Publishers, Hoboken.

[16] Parikh, J. and Shukla, V. (1995) Urbanization, Energy Use and Greenhouse Effects in Economic Development: Results from a Cross-National Study of Developing Countries. Angewandte Chemie, 54, 3932-3936. https://doi.org/10.1016/0959-3780(95)00015-G

[17] Alexiadis, S. (2012) "Endogenous Growth Theory" and "New Economic Geography”. Convergence Clubs and Spatial Externalities, 39-59. https://doi.org/10.1007/978-3-642-31626-5_3

[18] Li, Y., Chen, C., Wang, Y., et al. (2014) Urban-Rural Transformation and Farmland Conversion in China: The Application of the Environmental Kuznets Curve. Journal of Rural Studies, 36, 311-317. https://doi.org/10.1016/j.jrurstud.2014.10.005

[19] IPCC (2007) Contribution of Working Group to the Fourth Assessment Report of the Intergovernmental Panel on Climate Change 2007.

[20] Madlener, R. and Sunak, Y. (2011) Impacts of Urbanization on Urban Structures and Energy Demand: What Can We Learn for Urban Energy Planning and Urbanization Management? Sustainable Cities \& Society, 1, 45-53. https://doi.org/10.1016/j.scs.2010.08.006

[21] Zhang, C. and Lin, Y. (2012) Panel Estimation for Urbanization, Energy Consumption and $\mathrm{CO}_{2}$ Emissions: A Regional Analysis in China. Elsevier Science Inc., New York.

[22] Ehrlich, P.R. and Holdren, J.P. (1971) Impact of Population Growth. Science, 171, 1212. https://doi.org/10.1126/science.171.3977.1212

[23] Irfan, M. and Shaw, K. (2015) Modeling the Effects of Energy Consumption and Urbanization on Environmental Pollution in South Asian Countries: A Nonparametric Panel Approach. Quality \& Quantity, 51, 1-14.

[24] Hansen, B.E. (1999) Threshold Effects in Non-Dynamic Panels: Estimation, Testing, and Inference. Journal of Econometrics, 93, 345-368.

https://doi.org/10.1016/S0304-4076(99)00025-1 
[25] Nag, B. and Parikh, J. (2000) Indicators of Carbon Emission Intensity from Commercial Energy Use in India. Energy Economics, 22, 441-461. https://doi.org/10.1016/S0140-9883(99)00032-8

[26] Pachauri, S. and Jiang, L. (2008) The Household Energy Transition in India and China. Energy Policy, 36, 4022-4035. https://doi.org/10.1016/j.enpol.2008.06.016

[27] Holtedahl, P. and Joutz, F.L. (2004) Residential Electricity Demand in Taiwan. Energy Economics, 26, 201-224. https://doi.org/10.1016/j.eneco.2003.11.001

[28] York, R. (2007) Demographic Trends and Energy Consumption in European Union Nations, 1960-2025. Social Science Research, 36, 855-872.

https://doi.org/10.1016/j.ssresearch.2006.06.007

[29] Dietz, T. and Rosa, E.A. (1997) Effects of Population and Affluence on $\mathrm{CO}_{2}$ Emissions. Proceedings of the National Academy of Sciences of the United States of America, 94, 175-179. https://doi.org/10.1073/pnas.94.1.175

[30] Zhu, Q. and Peng, X. (2012) The Impacts of Population Change on Carbon Emissions in China during 1978-2008. Environmental Impact Assessment Review, 36, 1-8. https://doi.org/10.1016/j.eiar.2012.03.003

[31] Lin, B.Q. and Liu, X.Y. (2010) China's Carbon Dioxide Emissions under the Urbanization Process: Influence Factors and Abatement Policies. Economic Research Journal. 


\section{Appendix}

$\mathrm{CO}_{2}$ data was computed according to the formula from the IPCC, see below.

$$
C O_{2}=\sum_{i=1}^{8} C O_{2, i}=\frac{44}{12} \times \sum_{i=1}^{8} E C_{i t} \times e f_{i} \times o_{i}
$$

where $E C_{i t}$ represents standard coal for each type of energy resources in time $t$, $e f_{i}$ indicates carbon emission coefficient and $o_{i}$ is the rate of carbon oxidation.

We included a total of eight energy sources that are the main energy mix in China's energy consumption. Specifically, coal, coak, crude oil, fuel oil, kerosene, diesel and nature gas. The specification of carbon coefficient of each energy source are in Table A1 below.

Table A1. The energy sources are used in the study.

\begin{tabular}{cccc}
\hline Type of fuel & Standard coal coefficient & Carbon emission coefficient & Rate of carbon oxidation \\
\hline coal & 0.7143 & 0.756 & 0.913 \\
coke & 0.9714 & 0.855 & 0.928 \\
crude oil & 1.4286 & 0.586 & 0.979 \\
fuel oil & 1.4286 & 0.619 & 0.985 \\
gasoline & 1.4714 & 0.554 & 0.98 \\
kerosene & 1.4714 & 0.571 & 0.986 \\
diesel & 1.4571 & 0.591 & 0.982 \\
nature gas & 1.33 & 0.448 & 0.99 \\
\hline
\end{tabular}

